\title{
Free exchange of ideas \\ Experimenting with the open access monograph
}

Editor's note: Maria Bonn's essay, a review of the challenges of applying open access models to monograph publishing, is based on her presentation at the ALA 2010 Midwinter SPARC-ACRL Forum in Boston, MA. The entire Forum, "The ebook transition: Collaborations and innovations behind open-access monographs," may be viewed online at www.arl.org/sparc/meetings/ ala10mw/.

O pen access (OA) journals have made a good case that OA publishing can be economically viable and intellectually rigorous while increasing the circulation of research and ideas. That's an attractive trifecta to scholars and libraries and to those that fund them. In addition, the likely ripple effect of a better-informed public is exciting and easy to promote. While it is still easy to find skepticism about the economic sustainability and overall benefit of OA journal publishing, it has demonstrated enough potential that in recent years there is an increased level of curiosity, discussion, and even real publishing activity around applying OA models to monograph publishing. Such publishing is promising for supporting greater circulation and use of scholarly monographs and for potentially lowering costs, but this promise is, so far, under-informed by actual practice and documented results. For many of us who are interested in advancing the case for OA books, there was an initial flush of enthusiasm about the potential for such publishing that is now being tempered by awareness that books are not journals and monograph people are different from article people. It is important to learn from the experiments that are taking place, and to embark upon more of them, so that we can design distribution and publication models that meet the needs of our scholars and ensure the vitality of the monograph for as long as it continues to serve as a useful vehicle for communicating research and ideas.

Within the traditional university press structures that have generated a significant percentage of our scholarly monographs for the past century, books are expensive to produce and have little general market appeal. This results in prices that feel burdensome to libraries and that further curtails the potential for popular (even "popular" in academic circles) dissemination.

We hear, anecdotally, that while books are still required for tenure and promotion, it is increasingly difficult for junior humanities scholars to get such books published, that university presses are insupportable financial drains on their parent institutions, that these presses have drifted from mission in order to survive, and that print books compare poorly to the Web in terms of both speed and reach. All in all, the scholarly monograph

Maria Bonn is associate university librarian for publishing at the University of Michigan Library, e-mail: mbonn@umich.edu

Contact Mike Furlough—series editor, assistant dean for scholarly communications, and codirector of the Office of Digital Scholarly Publishing at Penn State University—with article ideas, e-mail: mfurlough@ psu.edu

(C) 2010 Maria Bonn 
has become a bit of a necessary headache for academe.

Enter the hope of the OA monograph. The crudest form of interest in OA book publishing tends to be of the "let's save some money" variety, vesting hope that free distribution, accompanied by sale of books printed only at time of purchase will radically lower costs. Publishers are quick to point out that if current acquisitions and production standards remain intact, such changes would only result in about 25 to 30 percent up front savings. (Administrators are equally quick to respond that 25 percent sounds pretty good). More sophisticated arguments for OA monographs promote the widespread dissemination of ideas, increased visibility for authors, a potential increase in print sales, and the possibility of online-first publication leading to a reinvented and less costly workflow for monograph production.

Even those most active in the OA monograph efforts (and I count myself as one of this number), or those most opposed to them, must concede that our arguments at present are informed mostly by speculation or ideology. Experimentation in open book publishing has been very limited and is still so new as to have generated few results that can be replicated or refuted.

The National Academies Press (NAP) has for ten years experimented in openness, giving away a basic version of their book content online and charging for additional functionality and more convenient formats. ${ }^{1}$ Their results indicate it is possible to meet mission, support openness and stay afloat, but NAP will be the first to assert that it does not bear the full costs of monograph production, nor does it make its books "open" by strict OA definitions. In fact, it imposes a number of use barriers to drive users toward sales of those more convenient formats.

Beyond NAP, OA book publishing in the United States has happened mostly at the level of an experimental volume or two, driven by powerful author persuasion, such as Yochai Benkler's Wealth of Networks or Lawrence Lessig's Free Culture, or in collaboration between university libraries and presses, with a fairly circumscribed content sets. Cornell's Signale series (two titles scheduled for late 2010), ${ }^{2}$ University of California's Flashpoint series (two titles), ${ }^{3}$ Penn State University's Romance Studies series (nine titles), ${ }^{4}$ and my own UM digitalculture books (13 titles) $)^{5}$ are all interesting, but limited examples of such efforts. The reborn Rice University Press, with its focus on free online versions and print sales, has generated great interest in the scholarly publishing community, but in its first four years has only published a little more than a dozen books, half of which are new editions of public domain materials. ${ }^{6}$

Outside the United States, where scholarly publishing is organized in ways that may be more amenable to open financial models, the experiments have more scale. Athabasca University Press list almost 50 titles in print and online for free on their Web site. ${ }^{7}$ Australian National University E Press produced more than 200 titles in six years, online for free and for sale in a variety of formats. ${ }^{8}$ OAPEN (Open Access Publishing In European Networks) ${ }^{9}$ is a coalition of European scholarly presses that believe "the time is ripe to bring the successes of scientific Open Access publishing to the humanities and social sciences," but to date their worthy efforts have focused on research and recommendations rather than actual book production.

Although traditional book publishers tend to exaggerate the point, most academic readers and writers (and promotion and tenure committees) do expect a lot of the scholarly monograph. They take editorial review and disciplinary vetting for granted. They expect placement in libraries and retail channels, promotion, and marketing and a basic standard of packaging that includes readable, correct text pleasantly designed and bound within an appealing cover. The value of any one of these functions, and whether and to what extent publishers meet these expectations, may be a matter of debate, 
but the baseline expectations remain, and for the foreseeable future we presume an OA book publisher (whether a start-up, or an established university press with a new model) must also attempt to meet them. And each of those things cost money to achieve. Moreover, the fledgling business models for OA books are often based on hope of revenue from format-specific sales, and it again costs money to produce those formats. One can argue, and I do, that those costs can be contained and are entirely supportable within the university economy, but until harder proof emerges, we exist in a hybrid economy where books must be made and must somehow make money even when they're being given away for free.

The scholarly monograph has a long tradition of the subvention that could potentially serve as a funding source for OA publishing, but I would venture that monograph authors more than article authors fear any taint of vanity publishing. It is currently of perceptible benefit to published scholars to demonstrate how hard it is to get published, since that difficulty continues to confer value on what they have already published. There is some fear that publishing a book for free, online, will just look too easy. The prestige fear factor is compounded by the fact that the largest and most respected university presses have, at the most, only dabbled in OA book publishing. Authors (and, in some cases, their senior mentors and colleagues) sense that this kind of publishing is simply not done by the best people.

Understanding this context can temper one's enthusiasm for OA as useful model for monograph publishing, but I use the word temper very deliberately. I do not mean to say that enthusiasm is being discouraged, but rather that it is being shaped and forged. Such realities should help us to create better OA publishing methods rather than driving us away from them.

I am a proponent of OA monographs, albeit a pragmatic one, and I count myself lucky to be a publisher at an institution that countenances some risk for the sake of in- novation. Faced with a dearth of successful models and robust data for OA book publishing and fully aware of the complexities confronting us, at the University of Michigan (UM) we have embarked upon some open book initiatives that fall into the category of "let's try some things and see what happens." These initiatives are departures from the status quo of scholarly book publishing, and they are explicitly intended to increase the vitality of the scholarship that such publishing should serve.

- UM Press in HathiTrust. The UM Press is the first university press to deposit almost the entirety of its content in HathiTrust, a collaborative repository for the digital collections of research libraries. Nearly 1,000 previously published volumes have already been deposited. More are added as digital files become available and appropriate rights are determined. Moving forward, UM Press will deposit all new content in HathiTrust, within a year of publication (and, in most cases, immediately upon publication). All the books are available for free searching and viewing and can be downloaded a page at a time. Any books available for sale also have a purchase option embedded within the viewing application. The books continue to be available for sale through all the conventional online and traditional distribution channels. We are very curious as to the effect of this free availability on sales, but our primary motivation in making these works available is to increase their access and use. ${ }^{10}$

- digitalculturebooks. digitalculturebooks is an imprint of the UM Library, coproduced by the UM Press and the Scholarly Publishing Office, dedicated to publishing innovative work in new media studies and the emerging field of digital humanities. The imprint aspires to both investigate and demonstrate new forms of scholarly practice in the humanities. The digital ambitions of this imprint are greater than the volumes made available through HathiTrust. While the HathiTrust volumes are online representations of the printed book, the digitalculturebook titles include hyperlinks, multimedia, and 
other features that take advantage of online delivery. All of its books pass through the traditional university press review and production process and are available online for free and are for sale in print and ebook formats.

We encourage digitalculturebooks authors to apply Creative Commons licenses to their work. We are interested in the impact of these licenses and of the free availability on sales and upon the visibility of the books. Although it is too early to report with certainty, it appears that in the majority of cases book sales are not harmed by the free online availability.

- Open Humanities Press (OHP). The university library, through its Scholarly Publishing Office, also partners with Open Humanities Press, an international OA publishing collective in critical and cultural theory. OHP organizes its volunteer editors around series. The editors recruit titles for their series and shepherd them through the review and development process. Manuscripts will be handed off to SPO for electronic and print production and delivery. The enterprise aims to create new venues for publication in cultural theory and to legitimize online publishing in the humanities.

It is quite innovative in its approach to distributing the labor of monograph production and its position on access, but has chosen to be quite traditional in its review process, in part to address academic humanities concerns about OA publishing and quality. The collective is poised to publish its first book, and we will be tracking closely on whether this distributed, largely volunteer approach to monograph publishing can be sustained. ${ }^{11}$

We will have to determine the value of these experiments and their financial viability over the course of months and years. With any published scholarship, the time to impact can vary immensely, and this is especially true of books that may be cited in other books that take years to see the light of day. By moving our press toward open offering of its content, we have also complicated the use of sales figures as a convenient measure of value. As we try to determine appropriate evidence for demonstrating the return on investment for university-supported publishing, metrics of usage will be an increasingly important factor.

As open book publishers, our financial outcomes are uncertain and our cultural location is not secure. Each of these experiments bears some risk, both in terms of revenue dollars and opportunity cost, but each carries with it the possibility of increasing access to scholarship and the certainty of teaching us more about the way in which the long form scholarly argument should be produced and circulated. And that, finally, is what the scholarly publisher is here to do.

Delivery formats and business models perpetually emerge and decline, but our imperative to transmit and promote the exchange of ideas remains.

\section{Notes}

1. Barbara Kline Pope and P. K. Kannan, A $n$ Evaluation Study of the National Academies Press's E-Publishing Initiatives: Final Report (Public Version), January 31, 2003,www.aaupnet.org/resources/mellon /nap/index.html.

2. Signale, signale.cornell.edu/.

3. Flashpoints, www.ucpress.edu/series. php?ser=ucfla.

4. Penn State Romance Studies, romancestudies.psu.edu.

5. digitalculturebooks, www.digitalculture. org/.

6. Rice University Press, ricepress.rice. $\mathrm{edu} /$.

7. Athabasca University Press, www. aupress.ca/.

8. Australian National University E Press, epress.anu.edu.au/.

9. Open Access Publishing In European Networks, www.oapen.org/.

10. The University of Michigan Press's titles can be accessed via HathiTrust at babel. hathitrust.org $/ \mathrm{cgi} / \mathrm{mb}$ ? $\mathrm{a}=$ listis; $\mathrm{c}=622231186$.

11. Open Humanities Press, openhumanitiespress.org/. n 